Wallace SJ. The child with febrile seizures. London: John Wright, 1988:109-26. Nelson KB, Ellenberg JH. Predictors of epilepsy in children who have experienced febrile seizures. $N$ Engl f Med 1976;295:1029-33.

3 Annegers JF, Hauser WA, Elveback LR, Kurland LT. The risk of epilepsy following febrile convulsions. Neurology 1979;29:297-303.

+ Verity CM. Butler NR, Golding J. Febrile convulsions in a national cohort followed up from birth. I. Prevalence and recurrence in the first five years of life. $B M 7$ 1985;290:1307-10

5 Verity CM, Butler NR, Golding J. Febrile convulsions in a national cohort followed up from birth. II. Medical history and intellectual ability at 5 years of age. BMY 1985;290:1311-5.

6 Chamberlain R, Chamberlain G, Howlett B, Claireaux A. British births 1970. Vol 1. The first week of life. London: William Heinemann, 1975.

7 National Institutes of Health. Febrile seizures: long term management of children with fever-associated seizures. Summary of an NIH consensus statement. $B M \mathcal{1}$ 1980;281:277-9.

8 Commission on Classification and Terminology of the International League Against Epilepsy. Proposal for revised clinical and electroencephalographic classification of epileptic seizures. Epilepsia 1981;22:489-501.

9 Wallace SJ. Factors predisposing to a complicated initial febrile convulsion. Arch Dis Child 1975:50:943-7.

10 Ross EM, Peckham CS, West PB, Butler NR. Epilepsy in childhood: findings from the national child development study. BMF 1980;280:207-10.

11 Annegers JF, Hauser WA, Shirts SB, Kurland LT. Factors prognostic of unprow.

(1987;316:

Secondary pathology of febrile and experimental convulsion In: Brazier MAB, Coceani $\mathrm{F}$, eds. Brain dysfunction in infantile febrile convulsions. New York: Raven, 1976:213-22.

13 Falconer MA, Serafetinides EA, Corsellis JAN. Etiology and pathogenesis of temporal lobe epilepsy. Arch Neurol 1964;10:233-48.

14 Taylor DC, Ounsted C. Biological mechanisms influencing the outcome of seizures in response to fever. Epilepsia 1971;12:33-45.

15 Wallace SJ. Spontaneous fits after convulsions with fever. Arch Dis Child 1977;52:192-6.

16 Reynolds EH. Early treatment and the prognosis of epilepsy. Epilepsia 1987;28:97-106

17 Lee K, Diaz M, Melchior JC. 'Temporal lobe epilepsy - not a consequence of childhood febrile convulsions in Denmark. Acta Neurol Scand 1981;63: 231-6.

18 Leviton A, Cowan LD. Do febrile seizures increase the risk of complex partial seizures? An epidemiologic assessment. In: Nelson KB, Ellenberg JH, eds. Febrile seizures. New York: Raven, 1981:65-74.

19 Rocca WA, Sharbrough FW, Hauser WA, Annegers JF, Schoenberg BS. Risk factors for generalized tonic-clonic seizures: a population-based case-control study in Rochester, Minnesota. Neurology 1987;37:1315-22.

(Accepted 25 September 1991)

\title{
Severe cystitis associated with tiaprofenic acid
}

\section{Ahmed, O W Davison}

\section{Kettering General Hospital, \\ Northamptonshire \\ NN16 8UZ \\ M Ahmed, FRCS, registrar in urology \\ O W Davison, FRCS, \\ consultant urologist}

Correspondence to: Mr Ahmed, 128 Knight's

Manor Way, Dartford, Kent DA1 5SP.

BMF 1991;303:1376
Cystitis, or inflammation of bladder mucosa, presents as urinary frequency, nocturia, and dysuria. Most cases of cystitis are infective, though local chemical inflammation may be responsible in some cases. We report three cases of severe cystitis associated with tiaprofenic acid.

\section{Case reports}

CASE 1

An 82 year old woman was prescribed triaprofenic acid $300 \mathrm{mg}$ twice a day in December 1987 for osteoarthritis. She was also taking bendrofluazide $5 \mathrm{mg}$ once a day. No previous allergy or intolerances were known. Within weeks of starting treatment with tiaprofenic acid she developed symptoms of urinary frequency, dysuria, and nocturia with a sterile pyuria and microscopic haematuria. She was given multiple antibiotics and topical oestrogens but none resolved the symptoms.

An intravenous urogram and urine cytology appeared normal and a urinary culture was negative for mycobacterium. Cystoscopy showed severe global cystitis. Histological examination of multiple bladder biopsy specimens showed that most of the bladder mucosa was replaced by inflammatory cell infiltrate in the submucosa, suggestive of interstitial cystitis. Tiaprofenic acid was discontinued and within two weeks her urinary symptoms had completely resolved. Cystoscopy six weeks later showed complete resolution of cystitis.

\section{CASE 2}

An 81 year old woman was prescribed sustained action tiaprofenic acid in October 1988. She had taken $2.5 \mathrm{mg}$ prednisolone once a day since 1973 for polyarthritis. Within a few weeks of starting tiaprofenic acid she developed cystitis with sterile pyuria. An intravenous urogram showed a partial duplex system on the left side. Analysis of blood chemistry and urine cytology gave normal results and a urine culture was negative for acid fast bacilli. Cystoscopy showed severe generalised cystitis. Four quadrant biopsy specimens showed oedematous stroma with diffuse infiltration of chronic inflammatory cells. The urothelium was completely lost, and special staining showed numerous mast cells, which suggested interstitial cystitis. Cystitis completely resolved on stopping tiaprofenic acid. CASE 3

A 69 year old woman was referred for urological consultation with a six month history of resistant cystitis. She had been taking sustained action tiaprofenic acid $300 \mathrm{mg} /$ day for the past eight months. She was also receiving beclomethasone and salbutamol by inhaler, slow release theophylline $400 \mathrm{mg} / \mathrm{day}$, and bendrofluazide $2.5 \mathrm{mg} /$ day. An intravenous urogram appeared normal. Cystoscopy showed generalised cystitis. Tiaprofenic acid was stopped and a repeat cystoscopy three weeks later confirmed that the cystitis had resolved. She remained free of bladder symptoms one year later.

\section{Comment}

Cystitis as a side effect of systemically administered drugs is rare. A Medline search from 1980 to 1990 yielded 12 reports, most of which related to cyclophosphamide. Other drugs implicated were danazol, which causes haemorrhagic cystitis in patients with hereditary angioneurotic oedema, ${ }^{1}$ and tranilast, an antiallergic drug, which causes eosinophilic cystitis'; one case of cystitis with kanamycin is reported in Russian. Nineteen cases of cystitis with tiaprofenic acid are registered with the Committee on Safety of Medicines.

Tiaprofenic acid is a non-steroidal anti-inflammatory drug of the propionic acid group. It is a potent inhibitor of prostaglandin biosynthesis through inhibition of cyclo-oxygenase. ${ }^{3}$ Tiaprofenic acid is metabolised in the liver, where about $5 \%$ is oxidised to phenol and alcohol derivatives. The parent compound and these metabolites are excreted in urine largely as acylglucuronides. The half life of the drug is short, and steady state is reached on the first day of the treatment.

The mechanism of tiaprofenic acid induced cystitis remains unknown. But awareness of this side effect is important as non-steroidal anti-inflammatory drugs are the most commonly prescribed drugs. In addition tiaprofenic acid induced cystitis could be confused with interstitial cystitis, the treatment of which is highly unsatisfactory and invasive.

\footnotetext{
1 Andriole GL, Brickman C, Lack EE, Sesterhenn IA, Javadpour N, Frank MM, al. Danazol induced cystitis: an undescribed source of hematuria in patients with hereditary angioneurotic edema. F Urol 1986;135:44-6.

2 Navada T, Ishikawa S, Sakamola M, Kalayama T, Iyarashi T, Fukuda T, et al. $\mathrm{N}-\left(3^{\prime}, 4^{\prime}\right.$-dimethoxicinnamovl) anthranillic acid, an antiallergic compound, induced eosinophilic cystitis. Urol Int 1986:41:457-64.

3 Sorkin EM, Brogden RN. Tiaprofenic acid. A review of its pharmacologica properties and therapeutic efficacy in rheumatic diseases and pain states. Drugs 1985;29:208-35.
}

Accepted 17 September 1991 